\title{
Two Piscan Aeromonas Vaccine Strategies
}

\author{
Ibrahim M S Shnawa ${ }^{1}$ Bshar E Ah Alsady ${ }^{2}$ Sermad Jalel ${ }^{2}$ \\ ${ }^{1}$ University Of Qasim College Of Biotechnology, Department of Biotechnology \\ Qasim, Babylon IRAQ. \\ ${ }^{2}$ Middle Technical University, Technical College of Agriculture, Mussiab. Babylon IRAQ. \\ ibrahimshnawa3@gmail.com
}

\begin{abstract}
A piscan Aeromonas ulcerative infection episode was revisiting Babylon province, IRAQ at 2018 following to that of 2015.. Two Aeromonas hydrophila vaccines are being developed and delivered in two strategies for common carp fish. First the heterologous prime-boost and second the homologous prime boost in combination with Alhagi Root Adjuvant[HRA] $3.5 \mathrm{gm} / \mathrm{kg}$ ration. These strategies were as, heat killed[AHKV] prime-live[AHLV] and HPA-AHLV prime-AHLV boost with immunogenicity group, infection group and sham controls in an aquaculture system provided with an optimal culture conditions. Both of Heterologous and homologous prime boost proved to be immunogenic as determined from A. hydrophila specific serum agglutinins which was of up to titre of 1280 and 2560 with survival rate of $100 \%$ and duration of immunity to three to six weeks post to the initial vaccination for the survived fish. The developmental evaluation criteria of both of vaccines were matching to that of other workers .In this aquaculture system. preconditioning with HPA for 21 days before vaccination was found comparable to vaccination with dead prime vaccine in the sense of; immunogenicity and survival rate and safety. Wider application of these two vaccination strategies in the natural conditions of commercial fish farming ponds is being an inherent need for confirmation of the present findings Key Words : Aeromonas ,Agglutinins ,Homologous ,Heterologous ,Strategy, Vaccines.

\section{Introduction}

The piscan Aeromonas infections are being evident problem in natural fish farming conditions in more than one geographic areas of the world $[1,2,3,4,5,6,7]$.The common carp ulcerative infection episode has been documented in this area[1 ].The humoral immune-modulating effects of gelatin ,carboxy methyl cellulose and chitin in the aquaculture of common carp fish have been determined[6,8]. Melano-macrophage centers have been tried as an infection marker among aquaculture of common carp fish[ 9 ].Currently, the pican ulcerative Aeromonas infection in carp fish was mapped again at 2018 in an episode form. The present work was aimed at presenting the development of two Aeromonas vaccine strategies in common carp fish aquaculture system.
\end{abstract}


Ibrahim M S Shnawa, Bshar E Ah Alsady, Sermad Jalel; Two Piscan Aeromonas Vaccine Strategies. Journal of Biomedical Engineering and Medical Imaging, Volume 6, No 1, February (2019), pp 20-27

\section{Materials And Methods}

\subsection{Natural Infection:}

\subsubsection{The Episode:}

Around 150 common carp fish were collected during the period of Sept. till Oct 2018. with an average weight of $100 \mathrm{gs}$ per each fish. Fish collect were made from a number of commercial fish farming bonds. Some of the sampled fish from different ponds appeared to be sluggish, weak with signs of skin ulceration, haemorrhage and descaling .On evisceration the internal organs were congested [10 ].

\subsubsection{Processing :}

Direct swabs were made from the affected skin lesions and processed for direct wet and stained films for microscopy and for culture as well as biochemical characterization(both classical and API20E)[11].

\subsection{Vaccine Development:}

From the clinically proven piscan ulcerative Aeromonas infectious disease, an Aeromonas-like colony morpho-type onto TCBS agar a representative colonies was picked quadrate streaked onto casein Aeromonas selective medium for purity and cultural characters. Then quadrate streaked onto brain heart infusion agar plate for more assurance of colony morphology and purity. Five similar colonies were transferred to brain heart infusion broth and incubated for $2 \mathrm{hr}$ at $37 \mathrm{C}$ to prepare the seed culture for biochemical tests[12].The results of both classical and API20E system were indicating the identification of Aeromonas hydrophila[13].From the pure identified A.hydrophila isolate onto BHIA plate dense inocula were transferred into $5 \mathrm{mls}$.BHIB broth medium in screw cape tubes in five replicates and layered with sterile liquid paraffin,then kept at $-18 \mathrm{C}$ in the chest freezer of the domestic refregirator as a stocks of the vaccine strains[14].

On time of the laboratory development of A.hydrophila vaccines, one stock culture tube was revived onto BHIB for overnight at $37 \mathrm{C}$, then onto TCBS at $37 \mathrm{C}$ for overnight. From growth onto TCBS, colonies were transferred by quadrate streaking onto BHIA plates. The vaccine seed culture was five colonies of similar morpho-types were elected and inoculated into each of two $50 \mathrm{ml}$ flask BIHB medium and incubated for $24 \mathrm{hrs}$ at $37 \mathrm{C}$.Growth for both flasks were checked for; viability, purity and viable counts[15 ].The whole culture viable counts were to determine the actual viable counts helpful in ratifying the number of vaccine units per $\mathrm{ml}$ of the prepared prototype vaccines.

For live culture vaccine broth culture was distributed into sterile centrifuge tubes in five $\mathrm{ml}$ amounts centrifuged at $5000 \mathrm{rpm}$ for $10 \mathrm{~min}$, and pellets were twice washed with sterile saline at $5000 \mathrm{rpm}$ for $10 \mathrm{~min}$.Pellets were reconstituted to have $1 \times 10$ to 7 vaccine units $/ \mathrm{ml}$ in the final dispensed vaccine in 5 $\mathrm{ml}$. screw capped tubes. This final lot vaccine tubes were checked for viability purity and safety[15].This prototype experimental live vaccine were used for short time experimentation and on due time.

For the dead vaccine version, the second flask BIHB viable counted culture was heated at $70 \mathrm{C}$ for one hour in water bath, then distributed in $5 \mathrm{ml}$ amounts in centrifuge tubes and centrifuged at 5000rpm for $10 \mathrm{~min}$. Pellets were twice washed with sterile saline at same centrifugation conditions. Then pellets were reconstituted to in rate of $1 \times 10$ to seven vaccine units per $\mathrm{ml}$. and dispensed in sterile screw capped tube in $5 \mathrm{ml}$ amounts which represent the final vaccine lot that was checked for purity and safety and kept at $4 \mathrm{C}$ for short term experimental use. 


\subsection{Adjuvant:}

Alhagi root adjuvant was prepared incorporated into the fish ration pills with rate of 3,5 gms per kg of the ration[16,17].

\subsection{Theme:}

The theme of the present work was to simulate a natural state of a commercial fish farming bonds one received dead vaccine and the other received immunostimulant. Both of the bonds have encountered natural concurrent repeated infection with A hydrophila. Based on this theme five groups each on ten fish in an aquaculture system, were assigned as: Heterologous prime-boost strategy group ,Homologous prime-boost in combination with HPA 3.5\% group, infection group, immunogenicity group and sham group. Immunogenicity was measure as agglutinin levels, efficacy jugged as serum humoral antibody levels and considered as a surrogate of immune protection [18] among test fish groups. Fish in each group at the assigned day of priming or boosting was inoculated in the third scale line under the dorsal fin intramuscularly at the day 22 and 37 of the experiment, Table 1.

Table 1 :Fish assignment groups

\begin{tabular}{|c|c|c|c|c|}
\hline Group & Nature & Protocol & Time table & No.of fish \\
\hline 1 & Immunogenicity & $\begin{array}{c}\text { Heat killed prime } \\
\text { boost }\end{array}$ & Day I,22,37 & 10 \\
\hline II & Infection & Saline-live-live & Day 22,37 & 10 \\
\hline III & $\begin{array}{c}\text { Heterologous } \\
\text { prime-boost }\end{array}$ & Dead-live-live & Day $1,22,37$ & 10 \\
\hline IV & $\begin{array}{c}\text { Adjuvant-live-live } \\
\text { Homologous } \\
\text { prime-boost }\end{array}$ & HPA-Live-live & Day 22,37 & 10 \\
\hline V & Sham & Nil & Nil & 10 \\
\hline
\end{tabular}

\subsection{Safety:}

Live vaccine within the limits of $1 \times 10$ to 3 up to $1 \times 10$ to 5 vaccine unit per $\mathrm{ml}$ was with any gross or histologic changes. The limit of vaccine units of live vaccine $1 \times 10$ to seven was the LD50 dose. Both vaccine strategies were being safe .

\subsection{Aquaculture System :}

Four common carp fish groups each of ten with an average body weight of 100 gms. These fish groups were kept during the experimentation period in an aquaculture system that were monitored in a weekwise manner for $\mathrm{PH}$, salt, weight and given minimal fed with continual shift of $\mathrm{O} 2$ ventilation and dynamic continuity[ 19].

\subsection{Serology:}

Fish blood samples were collected at the day 21,36 and 52, clotted and sera saved in composite sampling approach from test and control group of fish. Tube agglutination assays of test and control fish with vaccine antigens were made .Rise up of antibody titers up to three folds than the primary response of the dead antigen titer indicates immune adjuvant effect [20 ] . 
Ibrahim M S Shnawa, Bshar E Ah Alsady, Sermad Jalel; Two Piscan Aeromonas Vaccine Strategies. Journal of Biomedical Engineering and Medical Imaging, Volume 6, No 1, February (2019), pp 20-27

\subsection{Biometery:}

All of the biometric analysis for the test and control fish groups were assessed as in [21 ] .

\section{Results}

\subsection{Comparing Fish Groups:}

Sham group was designed to exclude non-specific abnormalities that may appearing on the test fish. Immunogenicity group was showing reasonable level of immune response level to heat killed vaccine. Infection group provides high immune response levels up to the titer of 2560 and $60 \%$ survival rate.

\subsection{Heterologous Prime Boost Strategy(HPBS):}

The primary immune responses of fish vaccinated with HPBS strategy was with titer of 320 .While the secondary immune response was with titer of 640,1280 and the titer was 20 at the day 60 the date of termination of experiment. Such titer profile is an evidence of immunogenicity. The dead vaccine alone was pure and safe. The HPBS has shown survival rate of $100 \%$. The relative calculated duration of immunity was six weeks since initial vaccine dose up to day 60.,Table 1 . The survived fish in this group was sacrificed at the day 60 was with neither gross nor histologic abnormal changes.

\subsection{HRA-Live-live Prime Boost(HRLPBS):}

The primary immune response of HRLPS fish was titer of 320 while the secondary immune response was with titer of 1280 , and the titer was 40 at the day 60 the day of termination of the experiment. Such titer profile was a proof for immunogenicity of HRLPBS.AHLV-HPA induced survival rate of $100 \%$ till the day 60 of the experiment. Evisceration of the test fish has shown neither gross nor histologic evidences for abnormalities. The relative duration of immunity of HRLPBS was three weeks since the initial vaccine dose., Table 2,Figure 1.

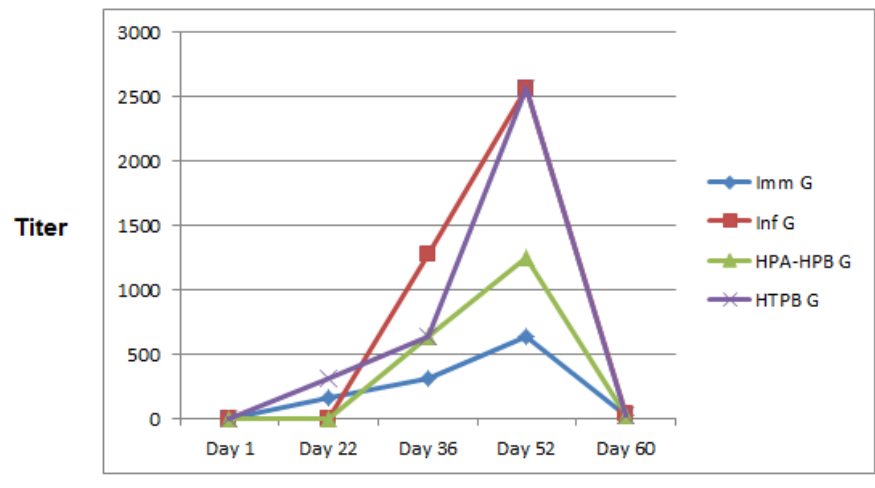

Duration of Immunity Via Serum Agglutinin titer

Figure 1 The fish immune response time curve

\subsection{Vaccine Developmental Parameters:}

The purity , safety ,immunogenicity and efficacy(Serum Agglutinins as a surrogate of efficacy) for both of the tested vaccine strategies, Tables 1 and 2 in their over- all criteria are parallel with that made by the other fish Aeromonas vaccine workers. ,Table 3.On comparing the HPBS to HRLPB, it was evident that both with the higher immunogenicity the higher survival rate and or efficacy. 
Table 2:Serum A.hydrophila agglutinin ,duration of immunity and survival rate of the heterologous prime-boost vaccine strategy.

\begin{tabular}{|l|l|l|}
\hline Vaccine Strategy & Time table & Parameters \\
\hline Dead prime-live boost & & \\
Prime & Day 1 & Titer :320 \\
Reading & Day 36 & Titer :640 \\
Boost & Day 37 & Titer :2560 \\
Reading & Day 52 & Titer : 20 \\
End point & Day 60 & - \\
Saline control & & 6 weeks \\
Relative duration of immunity & & $100 \%$ \\
Survival rate & & \\
\hline
\end{tabular}

Table 3 : Serum A hydrphila agglutinin.duration of immunity and Survival rate of Homologous prime boost vaccine strategy

\begin{tabular}{|l|c|c|}
\hline \multicolumn{1}{|c|}{ Vaccine Strategy } & Time table & Parameters \\
\hline HPA-prime live-boost live & & \\
Preconditioning with 3.5\% HPA & & \\
Live prime & 21 Days & \\
Reading & Day 22 & \\
Live boost & Day 36 & Titer :320 \\
Reading & Day 37 & \\
End point & Day 52 & Titer:1280 \\
Relative Duration of immunity & Day 60 & Titer : 20 \\
Survival rate & & 3 weeks \\
& & $100 \%$ \\
\hline
\end{tabular}

Table 4 : Criteria for the Laboratory Development of fish A hydrophila vaccines

\begin{tabular}{|c|c|c|c|c|}
\hline Criteria [15] & HPBS & HPA-HPBS & Formalin Killed[ 3] & Formalin Killed[ 4] \\
\hline $\begin{array}{l}\text { Understanding } \\
\text { Disease }\end{array}$ & Understandable & Understandable & Understandable & Understandable \\
\hline $\begin{array}{l}\text { Understanding } \\
\text { causal }\end{array}$ & Understandable & Understandable & Understandable & Understandable \\
\hline $\begin{array}{l}\text { Preparation of } \\
\text { candidate vaccine }\end{array}$ & Prepared & Prepared & Prepared & Prepared \\
\hline $\begin{array}{l}\text { Laboratory } \\
\text { development } \\
\text { Purity } \\
\text { Safety } \\
\text { Immunogenicity } \\
\text { Survival rate }\end{array}$ & $\begin{array}{l}\text { Pure } \\
\text { Safe } \\
\text { Immunogenic } \\
100 \%\end{array}$ & $\begin{array}{l}\text { Pure } \\
\text { Safe } \\
\text { Immunogenic } \\
100 \%\end{array}$ & $\begin{array}{l}\text { Pure } \\
\text { Safe } \\
\text { Immunogenic } \\
53-61 \% \text { up to } 100 \%\end{array}$ & $\begin{array}{l}\text { Pure } \\
\text { Safe } \\
\text { Immunogenic } \\
76.67 \%\end{array}$ \\
\hline
\end{tabular}

\section{Discussion}

Natural fish bacterial infections in commercial fish farming at Babylon province/IRAQ. and in any of which it stands as an ecologic and economic insults[ 22,23 ].Aeromonas ulcerative disease in common carp fish has been documented at 2015[ 1 ].New episode of the disease was noted in commercial fish farming bonds at 2018.A hydrophila was documented as the causal the situation was motivating to develop prototype A hydrophila vaccine candidate versions. Heat killed and live vaccine versions were being developed.The vaccine delivery to the test fish groups was through two vaccination 
Ibrahim M S Shnawa, Bshar E Ah Alsady, Sermad Jalel; Two Piscan Aeromonas Vaccine Strategies. Journal of Biomedical Engineering and Medical Imaging, Volume 6, No 1, February (2019), pp 20-27

strategies.Heat killed prime-live vaccine boost and Live prime-live boost incorporated with 3.5\% Alhagi root Powder adjuvant[16,17 ] .The reported immune efficacy for both of the vaccine strategies $100 \%$ which has been parallel to what have been found by others workers on A.hydrophila vaccines in fish aquaculture [3.4].The higher the immunogenicity, the higher survival rate(Efficacy).This may be attributed to antibody protective role[16,17] .

The two vaccine strategies have shown decline of agglutinin titers at the day 60 of the experiment thought the test fish in aquaria being normal till termination of experiment. This may be due to the phenomenon of sterile immunity, Table 6, were the antibody prevents pathogens from expressing their pathological effect [24,25], decline effector and/ or memory B cell functions or due the interplay of cellular immune factors in immune efficacy of these vaccine strategies. Though the latter possibility is far from being the case. Since Aeromonas is an extracellular pathogen[26 ]. Both of the vaccine candidate may contained TH2 epitopes or direct B cell epitopes[27 ].

Fish commercial vaccine safety in an aquaculture system should be safe for; fish wealth, consumer health and environmental hazard management[28, ].Fish vaccination strategies can be of short or long term protection [29] .The presented model in this study may be for short rather than for long term protection. Sham fish group was designed to watch the nonspecific factor that may lead to either morbidity or mortality in this aquaculture system.

Alhagi root adjuvant $3.5 \%$ in fish ration bear non-specific immunopotentiation effect[ 16,17$]$.Twice live vaccine doses in continuum with the test adjuvant rise up the immunogenicity and the efficacy of $A$. hydrophila vaccine in commercial carp fish[30]. The immunogenicity and protectivity is of an absolute correlate[18 ] in the both of the prime-boost strategies as apparent in this experimental fish aquaculture system, Table 5 .

Table5 : Correlation between serum agglutinins and protection[18].

\begin{tabular}{|l|l|}
\hline Term & Definition \\
\hline Absolute correlate & $\begin{array}{l}\text { A quantity of immune response to a vaccine that always provide near } 100 \% \\
\text { protection }\end{array}$ \\
\hline Relative Correlate & A quantity of immune response that usually but not always provide protection \\
\hline
\end{tabular}

Table 6 :Criteria for identification of sterile immunity induced by vaccination[24,25 ]

\begin{tabular}{|l|c|c|}
\hline Criteria & {$[24]$} & This Study \\
\hline Prevent infection & + & + \\
\hline $\begin{array}{l}\text { Prevent of } \\
\text { development and } \\
\text { clinical signs }\end{array}$ & + \\
symptoms & + \\
\hline $\begin{array}{l}\text { Prevent Pathological } \\
\text { Effects microbe }\end{array}$ & + & + \\
\hline $\begin{array}{l}\text { Prevent ND* } \\
\text { shedding }\end{array}$ & + \\
\hline
\end{tabular}

$*$ ND $=$ Not defined

The study theme proposed repeated infection events in natural conditions of fish farming bond are being expectable and the study design present a proof by aquaculture system were live vaccine initiate higher antibody levels and maximal survival rates. Advise may be issued as "let fish farmers fed the 
farmed fish with ration containing $3.5 \mathrm{gm} / \mathrm{kg}$ ration of Alhagi root powder, and they naturally encountered $A$ hydrphila repeated infection events leading to fish immunity. Though such issue need to be confirmed by wider application under the natural commercial fish pond environment.

\section{REFERENCES}

[1] Shnawa IMS, AL-Sadi B EAH.AL-Niaeem K $S$,A Piscan ulcerative Aeromonas infection.Int.Biol.Biomolecul.Agricul.Engin,2015 9(4):388-391.

[2] Marana MH , Jergensen LVG , Skov J , Chetti PW , Matteson AH . Delsgaard I, Kanld PW , Buchrran K ,Subunit vaccine candidate against Aeromonas salomonicida in rainbow trout Onchrhynchus mykiss.PoloONE,2017, 12(2):e0171944 dol.101371.

[3] Ruangpan L , Kitao J , Yoshida T, Protective efficacy of Aeromonas hydrophila vaccine in Nile tilapia Vet.immunol.Immunopathol.,1986,12(1-4):345-350.

[4] Prasad S, Areechon N,formalin killed Aeromonas hydrophila and Streptococcus vaccines in red Tilapia,Our Nature,2010,8(1):231-240.

[5] Viji VT, Volmurugan DS, Donio MBS, Jenifer JA, Babu MM , Citerasu T, .Vaccination strategies to protect goldfish Carassius against Aeromonas hydrophila infection.DAO,2013,104:45-47.

[6] Aly SM , ALButti AS, Rahmani AH , Atti NMA ,The response of new season Nile tilapia. Int.Clin.Exp.Med,2015 , $8(3): 4508-4514$.

[7] Kozinska A, Guz L , The effect of Aeromonas bestiarum vaccine on non-specific immune parameters and protection of carp(Cyprinus carpio) fish, Shelfish Immunol.,2004, 16:437-445.

[8] Shnawa IMS, ALSadi BEAH , ALNiaeem KS,Gelatin Chitin and carboxymethyl cellulose versus live Aeromonas hydrophila live bacterium as immunomodulant in common carp fish Cyprinus carpio, Exp.Rev.Vacc.Inform,2015, 2(1):62-66.

[9] ALNiaeem KS, Shnawa IMS .ALSadi BEAH ,The immunological response for spleen as a biomarker against Aeromonas hydrophila infection in carp fish Cyprinus carpio Bas.J.Vet,Res,2015, 13 (2):306-315.

[10] Roberts RJ ,Fish Pathology, $4^{\text {th }}$ ed,2012. Wiley Scientific Publications , UK.

[11] Ferchs GN ,The Isolation And identification of Fish Bacterial Pathogens.1984,University of Sterling,Scottland UK.

[12] MacFddin , Biochemical Identification of Medically Important Bacteria, $2^{\text {nd }}$ ed,2000,

[13] Microbe Online.API20E system: Introduction. procedures, results and interpretation. Biologics, clinical and commercial Supply .Patheon.2016. .

[14] Shnawa IMS, Maintenance of bacterial cultures, Sudi Med.J.1984,

[15] NIH ,Understanding Vaccines,Publication Number 98-4219.,22-24,1998.

[16] Jalel S,2019,Probable Immunomodulation Of AlHagi maourum Root Powder On Cyprinus L .,MSC Thesis ALFurat ALAwsat Techincal University Technical College of Agriculture,Musaib.Babylon/IRAQ. 
Ibrahim M S Shnawa, Bshar E Ah Alsady, Sermad Jalel; Two Piscan Aeromonas Vaccine Strategies. Journal of Biomedical Engineering and Medical Imaging, Volume 6, No 1, February (2019), pp 20-27

[17] ElSebai A, EIMurr AE , Glal GAA , AbdEl-Motaal ,Effect of ginger dietary supplementation and vaccine efficacy in Oreochromis niloticus with Aeromonas hydrophila, Slov.Vet.Res.,2018, 55(Suppl.20):31-39.

[18] Plotkin SA ,Correlates of vaccines induced immunity, Cli.Inf.Dis.,2008. 47(1):401-409.

[19] Olsen R , Svihus B , Criteria for safe plant ingridients in diet for aquaculture and fish.Opinion of Panl on of animal feed of Nerwigian Scientific Committee for food safety,VKM.2009.

[20] Stevens CD , Clinical Immunology And Serology : A Laboratory Perspective , $3^{\text {rd }}$ ed. 2010,F A Davis Company, Philadelphia.

[21] Steel RGD, Torrie JH, Dicky DA,Principles And Procedures of Statistics : A Biometeric Approach, $3^{\text {rd }}$ ed 1997,.McGraw-Hill INC.NY.

[22] Holvad LV ,Immunomodulants connecting innatand adaptive immunity in atlantic salmon Salmo solar , College of Fishery Science University Of Tormso.2007

[23] Kiron J , Fish immune system and nutritional modulation for prevention health care, Anim.Fed.Sci.Tech.,2012, 173(1-2): 111-113.

[24] Silva AP , Macedo AA , Costa LF , Rocha CE , Garcia LN et al,A Brucellosis vaccine that provides sterile immunity Plos ONE,Atlas Of Science Feb 2016.

[25] Cenrad NL, Mcbride , Souza JD, Silveira MM , Felix S, Mendonga KS ,Lig B subunit vaccine confers sterile immunity against challenge in hamster model of leptospirosis Plos ONE March 162017 1371,000544,

[26] Brooks GF,Carroll KC, Butel JS, Morse SA, Mietzner TA, Jawetz , and Adelbergs Medical Microbiology Review . $26^{\text {th }}$ ed 2013,McGraw-Hill Lange,NY.

[27] Owen JA, Punt J , Stranford SA, Jones PP,Kuby Immunology ,Macmillian NY,574-587.2013.

[28] Five M Editors Fish Site, Understanding Fish Vaccination.2006

[29] Committee for Medical Products for Veterinary Use,Europian Medicines Agency .Science Medicines Health, Guide lines and design of studies to evaluate the safety and efficacy of fish vaccines.2011.

[30] Ibrahem MD , Arab RMH, Mostafa MM, Rezk MA, Evaluation of different vaccine strategies for control of MAS in Nile Tilapia O.niloticus, $8^{\text {th }}$ Int .Symp. On Tilapia Aquaculture,2008,1157-1175. 